\title{
INDEKS KEPUASAN MASYARAKAT TERHADAP PELAYANAN PUBLIK PADA DINAS KEPENDUDUKAN DAN PENCATATAN SIPIL KOTA BANJARMASIN
}

\author{
Normajatun ${ }^{1)}$, Murdiansyah Herman ${ }^{2)}$ \\ 1) 2)FISIP, Universitas Islam Kalimantan MAAB (UNISKA) Banjarmasin \\ Email: normajatun63@gmail.com
}

\begin{abstract}
This study aimed to find out the description : the satisfaction of society's response to public service as well as service quality index value and the performance of the public service in the Departement of Civil Registration and Population of the City of Banjarmasin. The research using survey method and descriptively. Data collection using the questionnaire for respondents whit a simple technique random sampling. Descriptive data analysis with quantitative. The results showed the public generally satisfied with public service provided by the Departement of Civil Registration and Population of the City of Banjarmasin. The quality of service of the Departement of Civil Registration and Population are include in categories $B$, and the performance of his ministry is in good category either.
\end{abstract}

Keywords: satisfaction of society's, service quality

\section{PENDAHULUAN}

Peran pemerintah daerah dalam melaksanakan pelayanan publik diatur dalam Undang-Undang Nomor 23 Tahun 2014 tentang Pemerintahan Daerah, kemudian diperbaharui dengan Undang-Undang Nomor 2 Tahun 2015 tentang Penetapan PERPU Nomor 2 Tahun 2014 tentang Perubahan Atas Undang-Undang Nomor 23 tahun 2014 tentang Pemerintahan Daerah Menjadi Undang-Undang. Ketentuan ini mengandung spirit untuk terciptanya peningkatan pelayanan publik kepada masyarakat. Pelimpahan wewenang dari pemerintah pusat kepada pemerintah daerah memungkinkan terjadinya penyelenggaraan pelayanan dengan jalur birokrasi yang lebih ringkas dan memberikan peluang bagi pemerintah daerah dalam pemberian dan peningkatan kualitas layanan. Peraturan perundang-undangan tentang pelayanan publik mengatur fungsi, tugas dan wewenang serla tanggung jawab setiap instansi pemerintahan secara eksplisit tugas tersebut adalah memberikan pelayanan, yang berada dalam tataran pemerintah dengan segala hak, kewajiban, dari wewenang dan disisi lain memberikan kewajiban kepada publik sebagai penerima pelayanan. Sekaligus memberikan sanksi kepada publik yang melanggar ketentuan undang-undang (Sirajudin, 2011:20)

Pemberian pelayanan publik kepada masyarakat merupakan salah satu fungsi negara/pemerintah dalam upaya mensejahterakan masyarakat. Sejalan dengan pelaksanaan otonomi daerah di era reformasi, tuntutan akan perubahan good governance dan pelayanan publik yang prima merupakan prasyarat untuk mewujudkan kesejahteraan masyarakat. Menurut UU Pelayanan Publik Nomor 25 tahun 2009 pasal 1 pelayanan publik adalah kegiatan dalam rangka pemenuhan kebutuhan dasar sesuai dengan hak-hak sipil setiap warga negara dan penduduk atas suatu barang, jasa, dan atau pelayanan administrasi yang disediakan oleh penyelenggara pelayanan publik.

Dinas Kependudukan dan Pencatatan Sipil Kota Banjarmasin merupakan unsur pelaksana Pemerintah Daerah berdasarkan azas otonomi dan tugas pembantuan di bidang pelayanan administratif yang melayani urusan yang menyangkut kelengkapan data kependudukan dan catatan sipil, serta melayani pembuatan kartu keluarga (KK), KTP, akta kelahiran, perkawinan dan kematian untuk warga Kota 
Banjarmasin. Dinas Kependudukan dan Pencatatan Sipil Kota Banjarmasin dibentuk berdasarkan Peraturan Walikota Banjarmasin Nomor 28 Tahun 2011 tentang Pembentukan Organisasi dan Tata Kerja Perangkat Daerah. Demikian pula di dalam Peraturan Daerah Kota Banjarmasin Nomor 21 Tahun 2014 tentang Penyelenggaraan Administrasi Kependudukan meliputi Pendaftaran Penduduk dan Pencatatan Sipil merupakan pedoman bagi Dinas Kependudukan dan Pencatatan Sipil Kota Banjarmasin untuk melaksanakan pelayanan administrasi kependudukan. Pelayanan administrasi kependudukan sebagai salah satu pelayanan publik dasar yang sangat dibutuhkan masyarakat harus dipenuhi oleh pemerintah.

Di Kota Banjarmasin masih terdapat sebagian kecil masyarakat yang kurang memiliki kesadaran didalam kepemilikan dokumen kependudukan. Di sisi lain ada anggapan dari masyarakat bahwa pelayanan pada Dinas Kependudukan dan Pencatatan Sipil Kabupaten Kapuas tidak tepat waktu dan prosedur yang sulit dipahami oleh masyarakat. Selain itu masih ada masyarakat yang meminta bantuan orang lain (calo) dengan membayar sejumlah uang, padahal jika masyarakat memahami prosedur dan melengkapi persyaratan dokumen yang di perlukan dalam pembuatan dokumen kependudukan dan pencatatan sipil pada Dinas Kependudukan dan Pencatatan Sipil Kota Banjarmasin tidak di pungut biaya sama sekali atau gratis. Hal ini mengindikasikan pelayanan publik pada Dinas Kependudukan dan Pencatatan Sipil Kota Banjarmasin terdapat masalah yang berkenaan dengan kepuasan masyarakat terhadap kualitas dan kinerja pelayanan publik.

Untuk mengukur kualitas dan kinerja pelayanan publik pada Dinas Kependudukan dan Pencatatan Sipil Kota Banjarmasin di bidang administrasi kependudukan dan sekaligus untuk mengetahui kepuasan masyarakat terhadap pelayanan publik, maka dapat dilakukan penelitian tentang indeks kepuasan masyarakat pada Dinas Kependudukan dan Pencatatan Sipil Kota Banjarmasin. Untuk itulah penelitian ini dilakukan.
Penelitian ini ditujukan untuk mengetahui dan menggambarkan :

Kepuasan masyarakat terhadap pelayanan publik pada Dinas Kependudkan dan Pencatatan Sipil Kota Banjarmasin, dan Nilai indeks kualitas pelayanan dan kinerja pelayanan publik pada Dinas Kependudkan dan Pencatatan Sipil Kota Banjarmasin.

\section{METODE PENELITIAN}

Penelitian ini termasuk jenis penelitian dengan metode survei dan bersifat deskriptif, yaitu penelitian yang dilakukan pada populasi besar maupun kecil, tetapi data yang dipelajari adalah data dari sampel yang diambil dari populasi tersebut (Karlenger (1973) dalam Sugiyono (2012:7). Penelitian deskriptif adalah penelitian untuk mengetahui gambaran nilai variabel mandiri baik satu variabel atau lebih tanpa membuat perbandingan, atau menghubungkan antara variabel satu dengan variabel yang lain (Sugiyono,2012:7). Penelitian ini dilakukan pada Dinas Kependudukan dan Pencatatan Sipil Kota Banjarmasin.

Selanjutnya untuk menyebarkan angket kepada responden digunakan teknik Simple Random Sampling yaitu teknik penentuan sampel secara acak tanpa memperhatikan strata yang ada dalam populasi (Sugiyono, 2012:93), dalam penelitian ini anggota masyarakat yang sedang menerima pelayanan publik dalam bidang administrasi kependudukan pada Dinas Kependudukan dan Pencatatan Sipil Kota Banjarmasin, sebanyak 100 orang. Penelitian ini menggunakan analisis data deskriftif kuantitatif, yaitu data yang dikumpulkan melalui kuisioner dalam bentuk angka atau data kualitatif yang diangkakan (skoring) dan analisis data menggunakan penghitungan dengan rumusrumus statistik (Sugiyono,2012:14). kemudian disajikan dalam bentuk tabel frekuensi dan kemudian diberikan uraian sekaligus memberikan makna atau interpretasi untuk menjawab permasalahan yang telah dirumuskan. 


\section{HASIL DAN PEMBAHASAN}

\section{Kepuasan Masyarakat Terhadap Pelayanan Publik}

Penelitian mengenai indeks kepuasan masyarakat terhadap pelayanan publik pada Dinas Kependudukan dan Pencatatan Sipil Kota Banjarmasin didasarkan kepada sembilan indikator, setiap indikator mewakili satu item pertanyaan.
Persepsi masyarakat terhadap pelayanan publik dapat diketahui dari hasil perhitungan skor dari masing-masing responden. Dimana perhitungan dilakukan untuk mengetahui bagaimana kepuasan masyarakat terhadap pelayanan publik pada Dinas Kependudukan dan Pencatatan Sipil Kota Banjarmasin. Hasil dari perhitungan tersebut, dapat dilihat pada tabel berikut ini:

Tabel 1. Kepuasan Masyarakat Terhadap Pelayanan Publik

\begin{tabular}{clrr}
\hline No. & Keterangan & F & \% \\
\hline 1. & Tidak Puas & 7 & $7 \%$ \\
2. & Cukup Puas & 32 & $32 \%$ \\
3. & Puas & 54 & $54 \%$ \\
4. & Sangat Puas & 7 & $7 \%$ \\
\hline & Jumlah & 100 & 100,0 \\
\hline
\end{tabular}

Sumber: Analisis Data Primer 2017

Dari tabel 1 di atas, dapat diketahui bahwa sebagian besar masyarakat merasa puas terhadap pelayanan yang diberikan oleh pegawai pada Dinas Kependudukan dan Pencatatan Sipil Kota Banjarmasin.

Kemudian mengenai kepuasan masyarakat Kota Banjarmasin dilihat dari indikator pelayanan publik yaitu persyaratan pelayanan, prosedur pelayanan, waktu penyelesaian pelayanan, biaya pelayanan, produk spesifikasi jenis pelayanan, kompetensi pelaksana pelayanan, perilaku pelaksana pelayanan, maklumat pelayanan, dan penanganan pengaduan masukan dan saran. Untuk menentukan kepuasan masyarakat terhadap pelayanan publik pada setiap indikator, dilakukan dengan cara menghitung frekuensi dengan klasifikasi sebagai berikut :

Tabel 2. Klasifikasi Jawaban Responden

\begin{tabular}{clcr}
\hline No. & Keterangan & Skor & Mean \\
\hline 1. & Tidak Puas & 1 & $1,00-<0,75$ \\
2. & Cukup Puas & 2 & $0,75-<2,50$ \\
3. & Puas & 3 & $2,50-<3,25$ \\
4. & Sangat Puas & 4 & $3,25-<4,00$ \\
\hline & Jumlah & 100 & 100,0 \\
\hline
\end{tabular}

Sumber: Analisis Data Primer 2017

Berdasarkan tabel 2, maka kepuasan masyarakat dilihat dari indikator pelayanan publik adalah sebagai berikut : 
Tabel 3. Kepuasan Masyarakat dilihat dari Indikator Pelayanan Publik

\begin{tabular}{clrcr}
\hline No. & Keterangan & Skor & Mean & Mean \\
\hline 1. & Persyaratan pelayanan & 259 & 2,59 & Puas \\
2. & Prosedur pelayanan & 239 & 2,39 & Cukup Puas \\
3. & Waktu pelayanan & 240 & 2,40 & Cukup Puas \\
4. & Biaya/tarif pelayanan & 302 & 3,04 & Puas \\
5. & Produk spesifikasi jenis & & & \\
& pelayanan & 295 & 2,95 & Puas \\
6. & Kompetensi pelaksana & 290 & 2,90 & Puas \\
& pelayanan & 292 & 2,92 & Puas \\
7. & Perilaku pelaksana pelayanan & 276 & 2,76 & Puas \\
8. & Maklumat pelayanan & 288 & 2,88 & Puas \\
9. & Penanganan pengaduan & & 100 & 100,0 \\
\hline & Jumlah & & &
\end{tabular}

Sumber: Analisis Data Primer 2017

Dari tabel tersebut, dapat diketahui bahwa dari sembilan indikator pelayanan publik yang dapat memberikan kepuasan kepada masyarakat adalah persyaratan pelayanan, biaya pelayanan, produk spesifikasi jenis pelayanan, kompetensi pelaksana pelayanan, perilaku pelaksana pelayanan, maklumat pelayanan, dan penanganan pengaduan. Sedangkan untuk prosedur pelayanan dan waktu pelayanan hanya memberikan rasa cukup puas kepada masyarakat.

\section{Hasil Pengukuran Nilai Indeks Kualitas Pelayanan dan Kinerja Pelayanan Publik}

Untuk mengetahui nilai indeks kualitas pelayanan dan kinerja pelayanan Dinas Kependudukan dan Pencatatan Sipil Kota Banjarmasin, dilakukan penghitungan nilai indeks kepuasan masyarakat (IKM). dari unit pelayanan, yang mengacu pada sembilan indikator sesuai dengan KepMenPAN dan RB Nomor 16 Tahun 2014 tentang Pedoman Survei Kepuasan Masyarakat Terhadap Penyelenggaraan Pelayanan Publik.

Kesembilan indikator tersebut digunakan untuk mengukur persepsi 100 responden penelitian ini yang telah dimintai pendapatnya mengenai pengalamannya dalam memperoleh pelayanan publik pada Dinas Kependudukan dan Pencatatan Sipil Kota
Banjarmasin. Data yang diperoleh dari kuisioner diolah dalam data entri komputer.

Untuk memperoleh nilai indeks kepuasan masyarakat (IKM) unit pelayanan, dilakukan penghitungan nilai rata rata tertimbang pada masing-masing indikator atau unsur pelayanan dengan jenis data berupa data ordinal. Dalam penelitian ini menghitung indeks kepuasan masyarakat tehadap sembilan indikator atau unsur pelayanan yang dianalisis, setiap indikator pelayanan memiliki penimbang yang sama, dengan memakai rumus sebagai berikut :

$\underset{\text { tertimbang }}{\text { Babot nilai }}=\frac{\text { Jumlah bobot }}{\text { Jumlah unsur }}=\frac{1}{9}=0,111$

Selanjutnya dilakukan penghitungan dengan cara membagi total dari nilai persepsi per unsur dengan total unsur yang terisi, maka diperoleh hasil nilai rata-rata dari masingmasing unsur pelayanan yang dianalisis, dapat di lihat pada tabel berikut: 
Tabel 4. Nilai Rata-Rata Unsur Pelayanan

\begin{tabular}{clc}
\hline No. & Unsur Pelayanan & Mean \\
\hline 1. & Persyaratan pelayanan & 2,59 \\
2. & Prosedur pelayanan & 2,39 \\
3. & Waktu pelayanan & 2,40 \\
4. & Biaya/tarif pelayanan & 3,04 \\
5. & Produk spesifikasi jenis pelayanan & 2,95 \\
6. & Kompetensi pelaksana pelayanan & 2,90 \\
7. & Perilaku pelaksana pelayanan & 2,92 \\
8. & Maklumat pelayanan & 2,76 \\
9. & Penanganan pengaduan & 2,88 \\
\hline & Jumlah & 100 \\
\hline
\end{tabular}

Sumber: Analisis Data Primer 2017

Tabel 4 di atas menunjukkan hasil ratarata setiap indikator atau unsur pelayanan dari jawaban yang diberikan oleh 100 (seratus) responden yang telah memberikan pendapatnya terhadap sembilan indikator atau unsur yang menjadi obyek penelitian indeks kepuasan masyarakat ini.

Selanjutnya nilai indeks komposit (gabungan) untuk setiap unit pelayanan, merupakan jumlah nilai rata-rata dari setiap indikator atau unsur pelayanan dikalikan dengan penimbang yang sama, yaitu 0,111 dengan rumus sebagai berikut :

Total dari Nilai

Persepsi per Unsur

IKM $=$
Penimbang $\frac{\text { Total unsur yang terisi }}{X}$ Nilai
Berdasarkan rumus di atas diperoleh nilai indeks komposit (gabungan) adalah sebesar 2,753. Untuk memudahkan interpretasi terhadap nilai indeks kepuasan masyarakat yaitu antara 25 - 100 maka hasil penilaian tersebut di atas dikonversikan dengan nilai dasar 25 , dengan rumus sebagai berikut :

\section{IKM Unit Pelayanan x 25}

Untuk mengetahui Mutu Pelayanan dan Kinerja Unit Pelayanan adalah dengan berpedoman pada Keputusan MenPAN Nomor: KEP/25/M.PAN/2/2004 tentang Pedoman Umum Penyusunan Indeks Kepuasan Masyarakat Unit Pelayanan Instansi Pemerintah, sebagaimana tabel di berikut ini :

Tabel 5. Nilai Persepsi, Interval IKM, Interval Konversi IKM, Mutu Pelayanan dan Kinerja Unit Pelayanan

\begin{tabular}{ccccc}
\hline $\begin{array}{c}\text { Nilai } \\
\text { Persepsi }\end{array}$ & $\begin{array}{c}\text { Nilai } \\
\text { Interval } \\
\text { IKM }\end{array}$ & $\begin{array}{c}\text { Nilai Interval } \\
\text { Konversi IKM }\end{array}$ & $\begin{array}{c}\text { Mutu } \\
\text { Layanan }\end{array}$ & $\begin{array}{c}\text { Kinerja Unit } \\
\text { Pelayanan }\end{array}$ \\
\hline 1. & $1,00-1,75$ & $25-43,75$ & $\mathrm{D}$ & Tidak Baik \\
2. & $1,76-2,50$ & $43,76-62,50$ & $\mathrm{C}$ & Kurang Baik \\
3. & $2,51-3,25$ & $62,51-81,25$ & $\mathrm{~B}$ & Baik \\
4. & $3,26-4,00$ & $81,26-100,00$ & $\mathrm{~A}$ & Sangat Baik \\
\hline
\end{tabular}

Sumber : KepMenPAN 2004 
Berdasarkan penghitungan dari data dalam tabel 4, nilai indeks komposit (gabungan) diperoleh angka indeks tertimbang sebesar 2,753. Dengan demikian nilai indeks unit pelayanan hasilnya dapat disimpulkan sebagai berikut :

Nilai IKM setelah dikonversi $=$ Nilai Indeks $\mathrm{x}$ Nilai Penimbang $=2,753 \times 25=$ 68,825 .

Dengan nilai indeks kepuasan masyarakat (IKM) Unit Pelayanan (Nilai Interval Konversi IKM) 68,825. Apabila dikonfirmasikan dengan tabel 5 di atas maka dapat dikatakan Mutu Pelayanan Dinas Kependudukan dan Pencatatan Sipil Kota Banjarmasin adalah termasuk katagori B dan Kinerja Pelayanannya adalah termasuk katagori BAIK.

\section{REFERENSI}

Astuti, I. Y, 2015. Pengaruh Kualitas Pelayanan terhadap Kepuasan Masyarakat pada KantorDinas Kependudukan dan Pencatatan Sivil Kabupaten Blitar, Jurnal Cendikia, Volume 13 Nomor 7.

Barata, Atep Adya. 2012, Dasar-dasar Pelayanan Prima. Jakarta, Rayendra L. Toruan, Editor PT Elex Media Komputindo.

Kotler, Philip, dan Keller, Kevin Lane, 2010. Manajemen Pemasaran. jilid 1, Jakarta, Erlangga.

Pasolong, Herbani, 2014. Teori Administrasi Publik, Bandung, Alfa Beta.

Rahmayanti, Nina, 2013. Manajemen Pelayanan Prima. Yogyakarta, Graha Ilmu.

Ratminto, Winarsih, Atik S, 2012. Manajemen Pelayanan. Yogyakarta, Pustaka pelajar.

Sirajuddin, 2011. Hukum Pelayanan Publik Berbasis Keterbukaan Informasi dan Partisipasi. Malang, SetaraPress.

Sugiyono, 2012. Metode Penelitian Administrasi. Bandung, Alfa Beta.
Supranto, 2011. Pengukuran Tingkat Kepuasan Pelanggan. Jakarta, Reneke Cipta.

Tjiptono dan Chandra, 2012. Service, Quality, dan Satisfaction, Edisi 3, Yogyakarta, Penerbit Andi.

Umar, Husein, 2009. Metode Riset, Perilaku Konsumen Jasa. Jakarta, Ghalia Indonesia.

Yuninigsih, Tri, 2004. Dasar-Dasar Pelayanan Instansi Pemerintah Menuju Pelayanan Prima, Dialogue. JIAKP, Vol.1, No.1, Januari, 117130.

Undang-Undang Nomor 25 Tahun 2009 tentang Pelayanan Publik.

Keputusan Menteri Pendayagunaan Aparatur Negara Republik Indonesia Nomor 25 Tahun 2004 tentang Pedoman Penyusunan Indeks Kepuasan Masyarakat Unit Pelayanan Instansi Pemerintah.

Keputusan Menteri Pendayagunaan Aparatur Negara Republik Indonesia Nomor 16 Tahun 2014 tentang Pedoman Survei Kepuasan Masyarakat Terhadap Penyelenggaraan Pelayanan Publik.

Peraturan Pemerintah Nomor 96 Tahun 2012 tentang Pelayanan Publik.

Peraturan Daerah Kota Banjarmasin Nomor 21 Tahun 2014 tentang Penyelenggaraan Administrasi Kependudukan.

Peraturan Walikota Banjarmasin Nomor 28 Tahun 2011 tentang Pembentukan Organisasi dan Tata Kerja Perangkat Daerah. 